\title{
Design of Drive and Control System for "Bird"
}

\author{
Xiaoqing Zhang \\ State key Laboratory Of Ocean Engineering \\ Shanghai Jiaotong University \\ Shanghai, China, 200030
}

\author{
Weijing Zhang \\ State key Laboratory Of Ocean Engineering \\ Shanghai Jiaotong University \\ Shanghai, China, 200030
}

\begin{abstract}
In order to control the rotation of hydrofoils of "bird", further to control the position and orientation of marine seismic streamers, a design solution for drive and control system is provided in this paper. Worm Gear Drive mechanism is used as transmission mechanism, some sensors and intelligent meters are chosen to implement the data collection and communications. By using the configuration software of Kingview to realize the real-time monitoring. A test is carried out to testify the solution, the results of the test shows that the solution can meet the require of control for bird. But also some deficiencies need to be improved.
\end{abstract}

\section{Keywords-Bird, Marine seismic streamers, Hydrofoil}

\section{INTRODUCTION}

Seas and oceans contain rich oil and gas resources. The development and utilization of the Sea resources, especially oil and gas resources, has been evoked more and more great concern as the problem of energy becoming increasingly prominent. In order to development offshore oil and gas resources, undersea geological structure must be detected first. The current widespread method is the marine seismic exploration. As an important means for exploration of oil and gas resources, the marine seismic exploration can infer underground strata properties and forms through observation and analysis of the artificial-stimulate seismic response, because the elasticity and density of underground medium are different. Fig. 1 shows the marine seismic exploration system.[1]

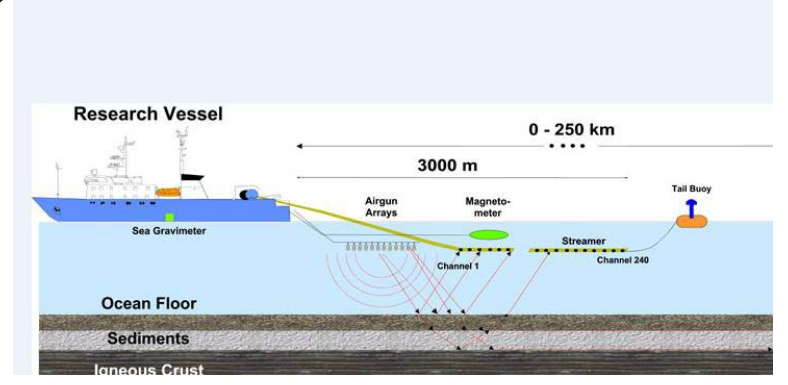

Figure 1. Marine seismic exploration

In order to improve the efficiency and precision of marine seismic exploration, further to meet the repeatability need of four-dimensional seismic exploration data, more cables and smaller space between adjacent cables are required. At the same time, when marine seismic system works underwater, as the influence of own negative buoyancy, ocean currents, towing geometric shape differences, the streamers will deviate from its intended depth and heading, that will reduce the measure precision of the system. In multiple systems, it can also cause system components to snarl and damage. Therefore, a set of active control device for posture and formations of streamers is needed to improve the accuracy of the exploration system.[2]

The "embedded-bird"[3][4] is a new type of manipulation positioning device for marine seismic exploration system. Comparison with suspended "bird", it connects with cables by embedding the cables. So it has the advantages of less resistance, smaller noise and horizontal spacing control ability.

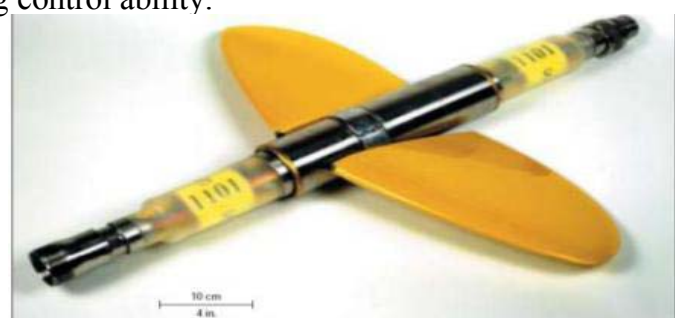

Figure 2. An embedded- bird

Fig.2[5] shows an "embedded-bird" produced by WesternGeco company. For this type of "bird", position controller collects the data and calculates the position of cables according to the space between underwater geophones. Navigation system calculates the actual position of cables with these data. Adjust controller controls each "bird" based on these data, and adjusts the cables to aim position. The calculation of horizontal position is based on all cables acoustic distance measure system, and the calculation precision can reach within the scope of 3 meters.

Fig. 3 shows a design solution for the "embeddedbird"[6]. In the intern circuit of "embedded-bird", the data acquisition module is mainly responsible for collecting data from depth sensor and the temperature sensor, digital compass makes a measurement on heading data and position data, communication module is responsible for communication, hydrofoil-drive control module is responsible for driving hydrofoils rotating, so as to control the "bird" and streamers. A design solution is provided in this paper. 


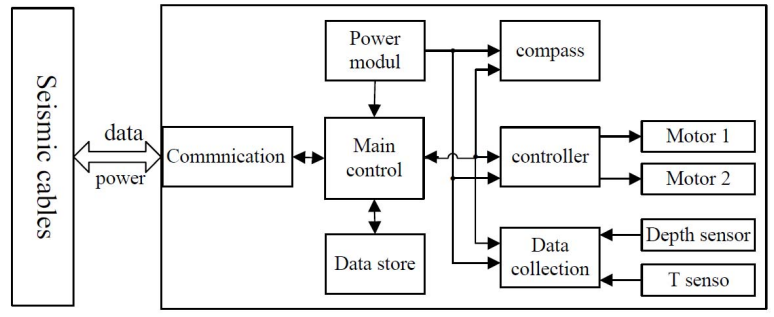

Figure 3. Controlling principle diagram

\section{Design Of Drive AND CONTROL Module}

Hydrofoil-drive and control module is mainly responsible for driving the rotation of hydrofoils. The design work mainly includes three parts: design of driven mechanisms, choice of hardware and design of control modules.

\section{A. CHOICE OF HARDWARE}

For particular applications of "embedded-bird", a servo motor with small size, large power and light quality is required, and the motor can accurately control its position and speed. After comparing with various brands of servo motor, the type of servo motor EPOS24/1 produced by Maxon company is meet the need and chosen to the drive motor.

As shown in Fig.4, the whole device has the advantages of small size and compact structure, it can meet all required applications of sorts of stroke and speed through the cooperation of motor, gear box and screw parameters.

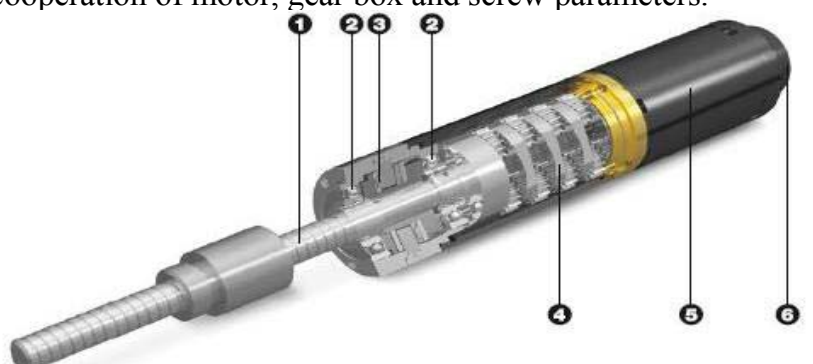

Figure 4. Servo motor of Maxon

\section{B. servo motor controller}

Servo motor need a special driving controller to drive and control its motion, EPOS24/1 is a position controller with small size and digital intelligent motion controller, shown as Fig.5.

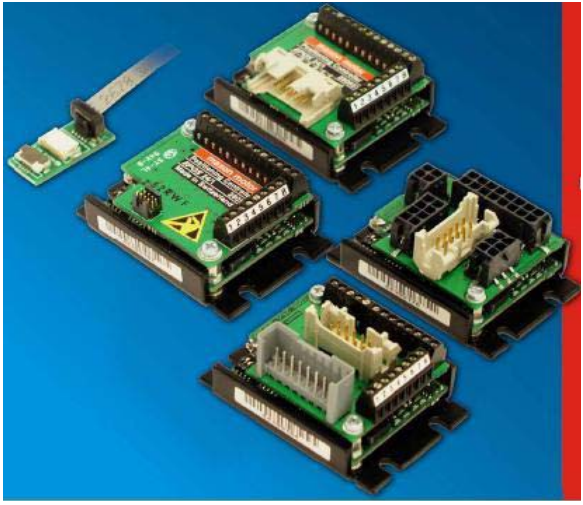

Figure 5. EPOS24/1

Its basic characteristics includes: position, velocity and current control mode; pulse, direction, host encoder digital position; feed forward control of speed and acceleration ; feedback signal of encoder and digital hall sensors (brushless motors), or encoder (brushless motor); single power supply; general I/O ports and analog input port.

\section{C. design of driven mechanisms}

A set of driven mechanism must be designed between motor and hydrofoil, which is used to turn the motor rotation movement into the rotation motion of the hydrofoil.

In this solution, a worm gear drive mechanism is used as transmission mechanism. As shown in Fig.6, it can turn motor rotation movement into the movement of hydrofoils well. At last, the internal arrangement plan of the driven mechanism of the hydrofoil can be shown as Fig.7.

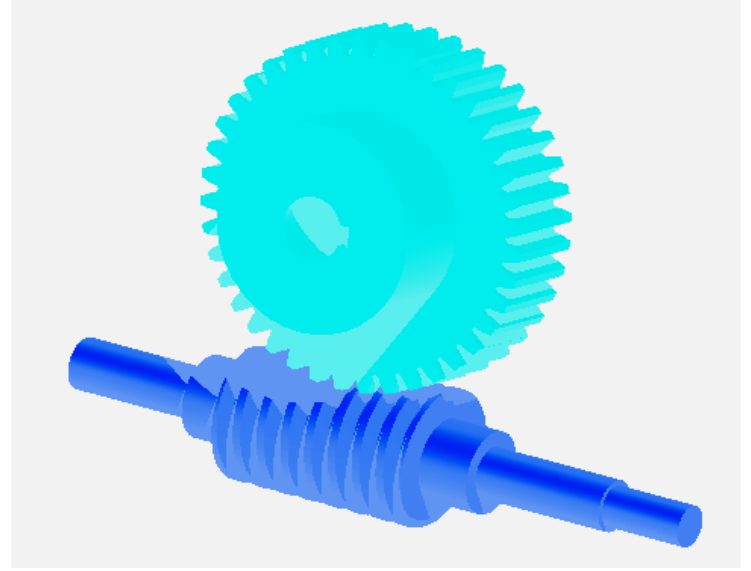

Figure 6. Gear transmission diagram 


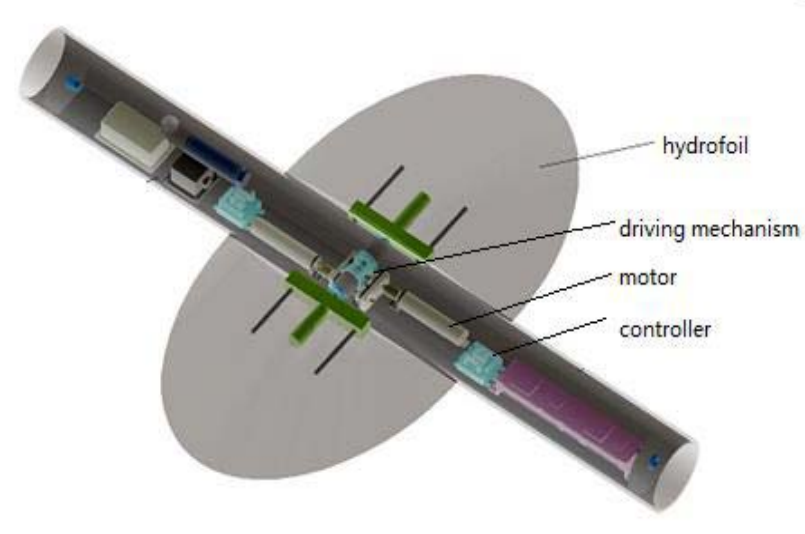

Figure 7. Arrangement plan diagram

\section{D. main control module}

Main control module is responsible for the data acquisition, data processing and communication management. Upper computer passes instructions to control the rotation of motors, different frequency correspondence with different speed, and the motor rotation direction should be controlled. For a good real-time control and convenience, the intelligent meter of ADAM -6024 is chosen as I/O module and the software of configuration software of KingView are used to monitoring program.

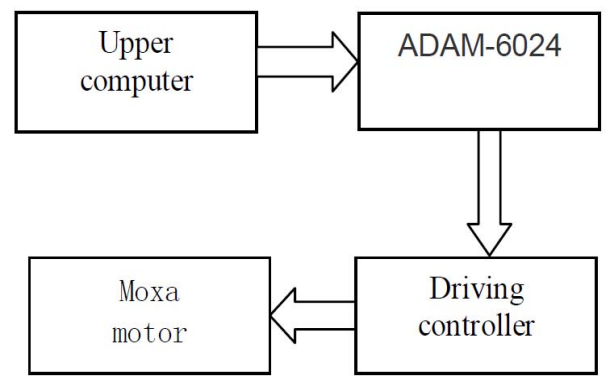

Figure 8. Control principle diagram

As shown in Fig.8, when it works, Upper computer with KingView sends pulse signals to I/O modules ADAM-6024, output ports of signal can be used to control the rotation of two motors respectively, and the other two analog signal ports are used to control the rotation direction respectively. The rotation speed of motors can be controlled by changing the frequency of the pulse signal produced by upper computer,

while the rotation direction can be controlled by changing the value of analog output ports. Then the system control objective can be completed.

\section{TEST AND CONCLUSIONS}

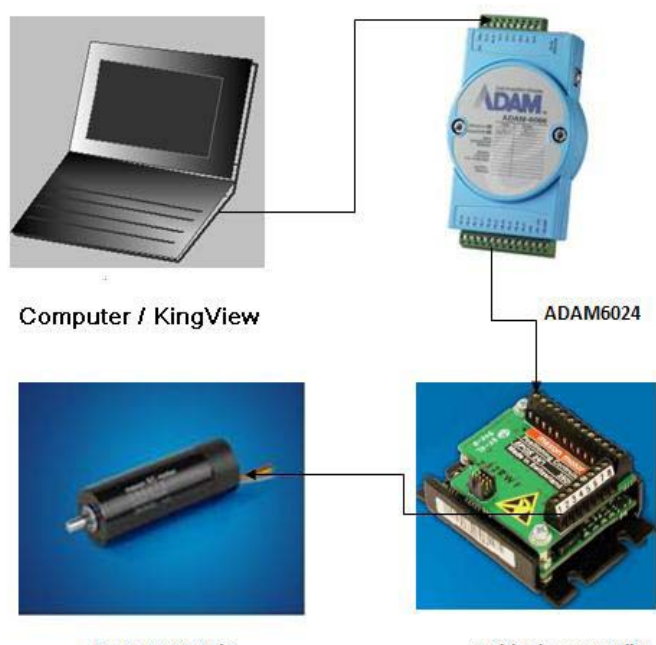

Moxa EPOS 24/1

positioning controller

Figure 9. Diagram of the test system

As shown Fig.9, a test has been carried out in the end to testify the solution. when debugging, different target values of hydrofoil angle within the scope of $-12^{\circ}-12^{\circ}$ are set in the upper computer, then the pulse signals are sent to ADAM-6024 which controls the motors rotating to target angle precisely. On working condition, a target depth is set, the upper computer controls the motors rotating and changing the attack angle of the hydrofoils of "bird", thus changing the lift provided by hydrofoils to drive "bird" movement. With depth sensor, the actual depth can get. Upper computer control the pulse signal, which controls the rotation speed and angle, according to the deviation between actual depth and target depth. When the "bird" reaches to the target depth, upper computer stops sending pulse signal and completes the control process. Usually PID control algorithm is used in this process.

From the results of the test, the conclusion can be described as following:

1) The solution provided by the paper is applicable. It meets the requirement of the system.

2) The worm gear drive mechanism is a good design and application. It has the advantage of self-locking function.

3) By using the the intelligent meter and Configuration Software make the control more simplified and convenient.

But a deficiency has been occurred during the test that the frequency of pulse generated by upper computer is different with different version of KingView, and usually hard to generate frequency high enough. It will have some influence on control of the motor. So some improvement should be proposed to solve this problem. In fact, by using the high-speed microcontroller as the main module can solve this problem because it can generate high-frequency pulses. The work of developing microcontroller is ongoing. 


\section{ACKNOWLEDGMENT}

This paper Supported by National Natural Science Foundation of China (51079083) and young teacher found of State Key Laboratory of Ocean Engineering.

\section{REFERENCES}

[1] Duan Lei, Zhang Weijing, Liu Tao. Marine seismic streamers positioning technology based on Acoustic positioning. Jiangsu university of science and technology journal .2010 .04

[2] Zhang Xiaoqing, Zhang Weijing, Chen Jun. Experimental Study On Hydrodynamic Characteristics Of Hydrofoil Of The Birds Embedded In Marine Seismic Streamers. OMAE 2010.6
[3] Andre W.Oliver, Robert E.Rouguette, Brien G.Rau .control device for an underwater cable [P].US 6525992 B1, Feb.25, 2003

[4] Andre W.Olivier, Bryant G.Ragan, James T.Cronvich. depth control device for an underwater cable [P].US 6016286, Jan.18, 2000

[5] Wang Fei. Simulation and control research of marine towed seismic system [D].Shanghai : Jiaotong university of Shanghai, 2006

[6] Yang Guikang. Design and development of embedded controlling system for the seismic streamer[D] .Shanghai: Jiaotong university of Shanghai, 2009 